\title{
A Study to Assess the Effectiveness of Structured Teaching Programme on Knowledge Regarding Complementary Therapy on Management of Hypertension among Hypertensive Patients Attending to Shirur Primary Health Centre Bagalkot District
}

\author{
Vinod M Kudari' ${ }^{1}$, Shilpa N Kugali², Deelip S Natekar ${ }^{3}$ \\ ${ }^{1}$ MSc (Nursing), Dept of community Health Nursing, B V V S Sajjalashree Institute of Nursing Sciences, \\ Navanagar, Bagalkot-587102 \\ ${ }^{2}$ Associate Professor, Dept of community Health Nursing, B V V S Sajjalashree Institute of Nursing Sciences, \\ Navanagar, Bagalkot-587102 \\ ${ }^{3}$ Principal, B V V S Sajjalashree Institute of Nursing Sciences, Navanagar, Bagalkot-587102
}

Corresponding Author: Deelip S. Natekar

DOI: https://doi.org/10.52403/ijshr.20220127

\begin{abstract}
Background of the Study: Hypertension is a cardiovascular disorder in which a person having high blood pressure over time. Those who are new to illness deal with fear, sorrow, and also lack of knowledge of the family members leads to more complications like recurrence. A study to assess the effectiveness of Structure Teaching Programme on knowledge regarding complementary therapy on management of hypertension among hypertensive patients attending to Shirur primary health center Bagalkot district.

\section{Objectives:}

1. A study to assess the Knowledge regarding complementary therapy on management of hypertension among hypertensive patient.

2. To assess the effectiveness of Structure Teaching Programme regarding complementary therapy on hypertension among hypertensive patients

3. To find out the association between post test knowledge score with selected sociodemographic variables.

Methodology: The pre-experimental one group pre test post test design was adopted for the present study. The sample for the present study includes 40 people from selected primary health
\end{abstract}

centre Shirur at Bagalkot District using simple random sampling technique. The data collected using structure close ended questionnaire and data was analyzed using descriptive and inferential statistics.

Results: The levels of knowledge regarding complementary therapy on management of hypertension among hypertensive patients. Reveals that, most of pre test people $(92.5 \%)$ had average knowledge (7.5\%) them had poor knowledge. Whereas in post test majority people (67.5) of the people had good knowledge level $(32.5 \%)$ of them had very good knowledge.

Similarly significant association was found between knowledge of hypertensive patients and demographic variables like gender $\left(\chi^{2}=1.11\right.$; $\mathrm{p}<0.05) \quad$ education $\quad\left(\chi^{2}=5.19 ; \quad \mathrm{p}<0.05\right)$ occupation $\left(\chi^{2}=3.56 ; \mathrm{p}<0.05\right)$ types of family $\left(\chi^{2}=0.80 ; \mathrm{p}<0.05\right)$.

Conclusion: Findings show that, there is significant difference in knowledge of management of hypertension among hypertensive patients. Thus, it is concluded that structure teaching programme should be administered to the hypertensive patients enhance knowledge regarding management of hypertension. 
Vinod M Kudari et.al. A study to assess the effectiveness of structured teaching programme on knowledge regarding complementary therapy on management of hypertension among hypertensive patients attending to Shirur Primary Health Centre Bagalkot District.

Key Words: Hypertension, Knowledge, Structure Teaching Programme

\section{INTRODUCTION}

Hypertension is the most important medical and public health issue. Worldwide it affects one billion people leading to 7.1 million deaths per year. Margaret Chan stated that "hypertension is a silent, invisible killer that rarely causes symptoms". Hypertension is defined as a persistent systolic blood pressure more than $140 \mathrm{~mm} \mathrm{hg}$ and diastolic blood pressure more than $90 \mathrm{~mm}$ of hg. Hypertension is one of the leading causes of death and disability among the global adult population. The higher incidence of hypertension damages the physical and economic health of the global community. In India, 196 million adult populations are affected with hypertension. Worldwide, 32 million people died due to noncommunicable diseases and among that 16.7 million died due to cardiovascular diseases (CVD). As per world hypertension league (WHL) 2009, 7 million people die every year due to high blood pressure and over 1.5 billion suffer from hypertension globally. The prevalence of hypertension was 59.9 and 69.9 per 1000 in male and female respectively. ${ }^{1}$

WHO (2016) stated that "970
million people worldwide have
hypertension. In the developed countries, 330 million people and 640 million in the developing countries have hypertension". Hypertension is rated as one the most important causes of premature death worldwide by who. The estimate of hypertension in 2025 will be 1.56 billion adults. Hypertension is responsible for $62 \%$ of cardiovascular diseases and $49 \%$ of ischemic heart disease affecting 25 to $30 \%$ of the urban population and 10 to $12 \%$ of the rural population in India with high blood pressure. Currently, 30\% are still unaware that they have hypertension and even though $59 \%$ are receiving treatment; only $34 \%$ have maintained the target blood pressure. ${ }^{2}$
The nursing care for hypertensive patients focuses on lowering and controlling the blood pressure without adverse effects and reduced cost. The nurse must support and teach the patient to adhere to the treatment regimen by implementing necessary lifestyle changes, taking medications as prescribed and scheduling regular follow up appointments with the heath care provider to monitor progress or identify and treat any complications of disease or therapy.

\section{Need For Study}

It has been long recognized that hypertension is an important risk factor for cardiovascular disease and mortality. Traditionally, a high burden of hypertension and its adverse consequences has been mistakenly thought to be an affliction of only economically developed countries. However, studies over the past two decades have reported the majority of people in many economically developing countries have blood pressure above the levels considered optimal with a high prevalence of hypertension present. Although a high prevalence of hypertension in all world regions has been previously reported, a recent publication from the Global Burden of Disease (GBD) Study has placed a renewed focus on the heavy toll high blood pressure is having in all regions of the world. ${ }^{3}$

World Health Organisation (WHO) statistics of 2015 shows that, the prevalence of hypertension among adults ( $\geq 18$ years) in India is $25.35 \%$ (25.9\% males and $24.8 \%$ females). ${ }^{3}$ Earlier, hypertension was a major problem of urban population but now it has spread to rural areas also and now it has become a major public health concern in India both in urban and rural areas. ${ }^{4}$

Hypertension is a global public health problem that estimates about $4.5 \%$ of overall disease burden. It is a general health challenge in economically developing and developed countries. High blood pressure prevalence is increased from $11.2 \%$ to $28 \%$ $(\mathrm{p}<0.001)$ and $23 \hat{a} €$ “ $42.2 \%$ in rural and 
Vinod M Kudari et.al. A study to assess the effectiveness of structured teaching programme on knowledge regarding complementary therapy on management of hypertension among hypertensive patients attending to Shirur Primary Health Centre Bagalkot District.

urban area according to the study done in Delhi for about 20 years. It is one of the important risk factors of cardiovascular disease, which is associated with morbidity and mortality. The aim was to identify the significant correlates of hypertension in a rural village in south India. ${ }^{5}$

Hence complementary therapy or alternative therapy reduces the risk of hypertension so researcher has selected this topic because for giving the awareness about the complementary therapy.

\section{OBJECTIVES OF THE STUDY}

1. A study to assess the knowledge regarding complementary therapy on management of hypertension among hypertensive patient.

2. To assess the effectiveness of structure teaching programme regarding complementary therapy on hypertension among hypertensive patients

3. To find out the association between post test knowledge score with selected socio-demographic variables.

\section{HYPOTHESIS}

H1. There is a significant difference between pre test and post test score of hypertensive patients regarding complementary therapy.

H2. There is a significant association between knowledge score of hypertensive patients regarding complementary therapy and selected socio demographic variables.

\section{ASSUMPTION:} assumption.

A study is based on the following

1. Hypertensive patients may have some knowledge regarding complementary therapy.

2. Structure teaching programme may improve the knowledge of hypertensive patients regarding complementary therapy.

3. Hypertension patient's knowledge regarding complementary therapy may vary with its selected demographic variables.
DELIMITATIONS: This study is delimited to,

- The study focused only on hypertensive patients.

- The study conducted duration is 6 weeks.

- Sample size 40 samples

\section{METHODOLOGY \\ Research Design}

It refers to the researchers' overall plan or blue print for obtaining an answer to the research hypothesis. It spells out the strategies that the researcher adopts to collect information that is accurate, objective and interpretable. It helps the researcher in defining attributes, selection of population, their manipulation and control observations to be made and type of statistical analysis to interpret the data. The research design used in this study is preexperimental one group pre test post test design.

\section{SELECTED VARIABLLES:} study are,

Variables selected for the present

- Independent variable: In the present study independent variable is structure teaching program on complementary therapy.

- Dependent variable: In the present study dependent variable is knowledge of hypertension.

Socio demographic variables of adolescents: Age, Gender, Religion, Dietary pattern, educational status, Occupation, Family monthly income. Source of information, complementary therapy, Duration of Disease, Personal habits, Treatment of hypertension

\section{Setting}

The setting is where the population are the portion of it being studied is located and where the study is carried out.

The present pilot study was conducted in Muchakhandi village by using simple random technique 4 sample have been taken for pilot study. 
Vinod M Kudari et.al. A study to assess the effectiveness of structured teaching programme on knowledge regarding complementary therapy on management of hypertension among hypertensive patients attending to Shirur Primary Health Centre Bagalkot District.

The present study was conducted in Shirur primary health centre at Bagalkot district by using simple random technique 40 sample have been taken for main study

\section{Population:}

- Target population: Target population for the present study is all the patients attending the Shirur primary health centre at Bagalkot district.

- Accessible population: Accessible population for the present study is hypertensive patients attending the Shirur primary health centre at Bagalkot district.

\section{Sample:}

In the present study consists of 40 hypertensive patients attending the Shirur primary health centre Bagalkot district.

\section{Sampling technique:}

Sampling technique is the process of selecting a portion of the population to obtain data regarding a problem. In the present study simple random sampling is used.

\section{Sample size:}

Final sample is determined by the after pilot study using power analysis. Through that calculated value the final sample size 40 hypertensive patients

\section{Criteria for sample selection:}

Inclusion criteria: The study includes who are;

1. Hypertension patients.

2. Who are available during the time of data collection.

3. Hypertension patient who all are willing to participate in the study.
Exclusion criteria: The study excludes who are;

1. Hypertension patients sick at the time of data collection.

2. Who have attended previous educational programme on complementary therapy.

3. Hypertension with diabetic mellitus.

\section{RESULT}

This chapter deals with analysis and interpretation of data collected from the sample i.e. 40 hypertensive patients selected primary health centre Bagalkot district. A structure close ended questionnaire was prepared and used for data collection and analysis was done with help of descriptive and inferential statistics

\section{Presentation of Data}

To begin with data was entered in a master sheet for tabulation and statistical processing the findings were presented under the following headings

Part-I: Description of sample with their socio-demographic variables.

Part-II Assessment of levels of knowledge regarding complementary therapy on management of hypertension among hypertensive patients attending to Shirur primary health centre Bagalkot district

Part-III: Area wise mean, SD, of knowledge score of hypertensive patients regarding complementary therapy

Part-IV: Assessing effectiveness of STP on $T$ test values and $P$ test value

Part -V. Association of knowledge score of people with their Socio-demographic Variables

Part-I: Description of sample with their socio-demographic variables.

\begin{tabular}{|l|l|l|}
\hline Age & Frequency & Percentage \\
\hline $31-40$ & 1 & $2.5 \%$ \\
\hline $41-50$ & 6 & $15 \%$ \\
\hline $51-60$ & 15 & $37.5 \%$ \\
\hline $61-70$ year or above & 18 & $45 \%$ \\
\hline Gender & Frequency & Percentage \\
\hline Male & 28 & $70 \%$ \\
\hline Female & 12 & $30 \%$ \\
\hline Religion & Frequency & Percentage \\
\hline Hindu & 31 & $77.5 \%$ \\
\hline Muslim & 7 & $17.5 \%$ \\
\hline Christian & 2 & $5 \%$ \\
\hline Any other specify & - & \\
\hline
\end{tabular}


Vinod M Kudari et.al. A study to assess the effectiveness of structured teaching programme on knowledge regarding complementary therapy on management of hypertension among hypertensive patients attending to Shirur Primary Health Centre Bagalkot District.

\begin{tabular}{|c|c|c|}
\hline \multicolumn{3}{|l|}{ Table Continued... } \\
\hline Educational status & Frequency & Percentage \\
\hline Primary & 10 & $25 \%$ \\
\hline Middle & 9 & $22.5 \%$ \\
\hline Secondary & 8 & $20 \%$ \\
\hline PUC & 6 & $15 \%$ \\
\hline Graduate & 7 & $17.5 \%$ \\
\hline Present occupation of participant & Frequency & Percentage \\
\hline Farmer & 25 & $62.5 \%$ \\
\hline Teacher & 6 & $15 \%$ \\
\hline Others & 9 & $22.5 \%$ \\
\hline Types of family & Frequency & Percentage \\
\hline Nuclear & 20 & $50 \%$ \\
\hline Joint & 12 & $30 \%$ \\
\hline Extended & 6 & $15 \%$ \\
\hline Single & 2 & $5 \%$ \\
\hline Marital status & Frequency & Percentage \\
\hline Married & 38 & $95 \%$ \\
\hline Unmarried & - & \\
\hline Divorced or separated & 2 & $5 \%$ \\
\hline Widow or widower & - & \\
\hline Dietary pattern & Frequency & Percentage \\
\hline Vegetarian & 12 & $30 \%$ \\
\hline Non vegetarian & 14 & $35 \%$ \\
\hline Mixed & 14 & $35 \%$ \\
\hline Monthly income of the family in rupees & Frequency & Percentage \\
\hline $1000-3000$ & - & \\
\hline $3001-5000$ & 3 & $7.5 \%$ \\
\hline $5001-10000$ & 15 & 37.5 \\
\hline Above 10000 & 22 & $55 \%$ \\
\hline How long have you been diagnosed with hypertension & Frequency & Percentage \\
\hline$<1$ year & 2 & $5 \%$ \\
\hline $1-3$ year & 12 & $30 \%$ \\
\hline $4-6$ years & 10 & $25 \%$ \\
\hline 6 years and above & 16 & $40 \%$ \\
\hline Is any of your family members has a history of hypertension & Frequency & Percentage \\
\hline Yes & 16 & $40 \%$ \\
\hline No & 24 & $60 \%$ \\
\hline
\end{tabular}

PART-II: Assessment of levels of knowledge regarding complementary therapy on management of hypertension among hypertensive patients attending to Shirur primary health centre Bagalkot district

Categorization of the people on the basis of the level of knowledge was done as follows: scores 25-30 very good knowledge level, score 19-24 Good knowledge level, score 13-18 average knowledge level, score 07-12 poor knowledge level, score 0-6 very poor knowledge level,

Table 1: Pre test Levels of knowledge regarding complementary therapy on management hypertension $\mathbf{N}=\mathbf{4 0}$ Level of knowledge e

\begin{tabular}{|l|c|c|c|}
\hline Level of knowledge e & Item & F & \% \\
\hline Very good & $0-6$ & 0 & $0 \%$ \\
\hline Good & $7-13$ & 0 & $0 \%$ \\
\hline Average & $13-18$ & 37 & $92,5 \%$ \\
\hline Poor & $19-24$ & 3 & $7.5 \%$ \\
\hline Very poor & $25-30$ & 0 & $0 \%$ \\
\hline
\end{tabular}

The levels of knowledge regarding complementary therapy on management of hypertension among hypertensive patients.
Reveals that, most of pre test people $(92.5 \%)$ had average knowledge $(7.5 \%)$ them had poor knowledge there were no people who had very poor, good, very good regarding complementary therapy.

Table 2: Post test Levels of knowledge regarding complementary therapy on management hypertension $\mathrm{N}=\mathbf{4 0}$

\begin{tabular}{|l|c|c|c|}
\hline Level of knowledge & Item & F & \% \\
\hline Very good & $0-6$ & 13 & $32.5 \%$ \\
\hline Good & $7-12$ & 27 & $67.5 \%$ \\
\hline Average & $13-18$ & 0 & $0 \%$ \\
\hline Poor & $19-24$ & 0 & $0 \%$ \\
\hline Very poor & $25-30$ & 0 & $0 \%$ \\
\hline
\end{tabular}

Categorization of the people on the basis of the level of knowledge was done as follows: scores 25-30 very good knowledge level, score 19-24 Good knowledge level, score 13-18 average knowledge level, score 07-12 poor knowledge level, score 0-6 very poor knowledge level,

The levels of knowledge regarding complementary therapy on management of hypertension among hypertensive patients. 
Vinod M Kudari et.al. A study to assess the effectiveness of structured teaching programme on knowledge regarding complementary therapy on management of hypertension among hypertensive patients attending to Shirur Primary Health Centre Bagalkot District.

Where as in post test majority (67.5) of the people had good knowledge level $(32.5 \%)$ of them had very good knowledge level and there were no people who had very poor, poor, average, regarding complementary therapy

Table 3 Area wise mean, SD, of knowledge score of hypertensive patient regarding complementary therapy, $\mathbf{N}=40$

\begin{tabular}{|l|l|l|l|l|l|}
\hline \multirow{2}{*}{ Knowledge area } & \multirow{2}{*}{ Max score } & \multicolumn{2}{|c|}{ Pre test } & \multicolumn{2}{c|}{ Post test } \\
\cline { 3 - 6 } & & Mean & SD & Mean & SD \\
\hline Regarding hypertension & 14 & 20.17 & 3.35 & 26.17 & 2.18 \\
\hline Regarding dash Diet & 11 & 18.54 & 1.57 & 25.45 & 1.80 \\
\hline Regarding relaxation therapy & 05 & 18.6 & 1.14 & 26.5 & 2.68 \\
\hline Total & 30 & 57.28 & 6.66 & 78.12 & 6.06 \\
\hline
\end{tabular}

The area wise Mean, and SD of knowledge score hypertensive patients reveals that, the pre-test questions regarding hypertension mean is $20.17 \%$ and SD $3.35 \%$ and the questions regarding dash diet mean is $18.5 \%$ and SD $1.57 \%$ and the regarding relaxation therapy mean is $18.6 \%$ and SD $1.14 \%$ and post test questions regarding hypertensions mean $26.17 \%$ and SD $2.18 \%$ and questions regarding dash diet mean is $25.45 \%$ and SD $1.80 \%$ and the questions regarding relaxation therapy mean is $26.5 \%$ and SD $2.68 \%$ total mean of knowledge scores of hypertensive patients was pre-test $57.28 \%$ and SD $6.66 \%$ and the post-test mean knowledge scores $78.12 \%$ and SD 6.06.

\section{Part -III: Assessing the Effectiveness of STP On T Test and P Values}

This result showed pre test and post test values of the $\mathrm{T}$ test and $\mathrm{P}$ values of the result is significant. It represents that there is highly effectiveness about complementary therapy upon pre test to post test knowledge score. So, H1 is accepted

Table 4 Assessing the effectiveness of STP on T test and P test values

\begin{tabular}{|l|l|}
\hline T TEST & P VALUES \\
\hline 13.09 & $<.001$. \\
& $<.05$ \\
\hline
\end{tabular}

H1. There is a significant difference between pre test and post test score of hypertensive patients regarding complementary therapy.

\section{Part IV. Association of knowledge score of people with their Socio-Demographic variables}

To find out association of the knowledge score of people with their sociodemographic variables a research hypothesis was formulated

Table 6.5 Association of knowledge score of people with their socio-demographic variables, $\mathrm{N}=40$

Table 6.5 Association of knowledge score of people with their socio-demographic variables, N=40
\begin{tabular}{|l|l|l|l|}
\hline Demographic variables & Value of chi-square & P value & Level of significant \\
\hline Age & 0.103 & 0.748 & $\mathrm{NS}$ \\
\hline Gender & 1.111 & 0.291 & $\mathrm{NS}$ \\
\hline Religion & 0.334 & 0.563 & $\mathrm{NS}$ \\
\hline Education & 5.198 & 0.022 & $\mathrm{~S}$ \\
\hline Occupation & 3.563 & 0.059 & $\mathrm{~S}$ \\
\hline Types of family & 0.806 & 0.369 & $\mathrm{NS}$ \\
\hline Marital status & 0.401 & 0.526 & $\mathrm{NS}$ \\
\hline Dietary pattern & 0.334 & 0.562 & $\mathrm{NS}$ \\
\hline Family monthly income & 0.173 & 0.677 & $\mathrm{NS}$ \\
\hline How long have been diagnosed with hypertension & 0.334 & 0.562 & $\mathrm{NS}$ \\
\hline Is any of your family member has a history of hypertension & 0.019 & 0.888 & $\mathrm{NS}$ \\
\hline
\end{tabular}

The association of the knowledge score of people with their sociodemographic variables shows that, there is significant association found between the knowledge of hypertensive patients with their demographic variables like education, occupation $\mathrm{p}<0.05)$ occupation $(\mathrm{x}=3.56$; $\mathrm{p}<0.05)$ types of family $(\mathrm{x}=0.80 ; \mathrm{p}<0.05)$.
And no significant association found between knowledge of hypertensive patients with their demographic variables like age, gender, religion, types of family, marital status, dietary pattern, family monthly income, how long have been diagnosed with hypertension, Is any of your family member has a history of hypertension. 
Vinod M Kudari et.al. A study to assess the effectiveness of structured teaching programme on knowledge regarding complementary therapy on management of hypertension among hypertensive patients attending to Shirur Primary Health Centre Bagalkot District.

H2. There is a significant association between knowledge score of hypertension patients regarding complementary therapy and selected socio-demographical variable

\section{CONCLUSION}

The following conclusions were drawn on the basis of the findings of the study.

The levels of knowledge regarding complementary therapy on management of hypertension among hypertensive patients. Reveals that, most of pre test patients $(92.5 \%)$ had average knowledge $(7.5 \%)$ them had poor knowledge there were no patients who had very poor, good, very good regarding complementary therapy. Where as in post test majority (67.5) of the patients had good knowledge level $(32.5 \%)$ of them had very good knowledge level and there were no patients who had very poor, poor, average, regarding complementary therapy.

\section{Recommendations}

Based on the findings of the study the following recommendations are made

1. A similar study can be conducted among medical health educators, School teachers, Anganwadi workers and Village leaders.

2. Effectiveness of teaching programmes to teach family members of hypertensive patients on basic knowledge on hypertension may be tested.

3. Follow-up study can be conducted to evaluate the effectiveness knowledge regarding complementary therapy of structure teaching programme.

4. There is need and scope for counseling services to be offered to family members and their hypertensive patients.

\section{Acknowledgement: None}

Conflict of Interest: None

\section{Source of Funding: None}

\section{Ethical Approval: Approved}

\section{REFERENCES}

1. Adhana, R., Gupta, R., Dvivedii, J., \& Ahmad, S. The influence of the 2:1 yogic breathing technique on essential hypertension. Indian Journal of Physiology and Pharmacology, 57(1), 38-44, 2016.

2. Lackland DT, Weber MA. Global burden of cardiovascular disease and stroke: hypertension at the core. Can J Cardiol. 2015 May;31(5):569-71. doi: 10.1016/j.cjca.2015.01.009. Epub 2015 Jan 22. PMID: 25795106.

3. Bromfield S, Muntner P. High blood pressure: the leading global burden of disease risk factor and the need for worldwide prevention programs. Curr Hypertens Rep. 2013;15(3):134-136. doi:10.1007/s11906-013-0340-9

4. The World Health Report 2002. Reducing risks, promoting healthy life. https://apps.who.int/iris/bitstream/handle/10 665/42510/WHR_2002.pdf

5. Veientlena, S., and P. P. "Prevalence Of Hypertension And Determination Of Its Risk Factors In Korangrapady, Udupi District, Coastal Karnataka, India”. Asian Journal of Pharmaceutical and Clinical Research, vol. 11, no. 6, June 2018, pp. 51721, doi:10.22159/ajpcr.2018.v11i6.24727.

How to cite this article: Kudari VM, Kugali SN, Natekar DS. A study to assess the effectiveness of structured teaching programme on knowledge regarding complementary therapy on management of hypertension among hypertensive patients attending to Shirur Primary Health Centre Bagalkot District. International Journal of Science \& Healthcare Research. 2022; 7(1): 159-165. DOI: https:// doi.org/10.52403/ijshr.20220127 